\title{
Problems with the term and concept of "abuse": critical reflections on the Scottish Adult Support and Protection study
}

\section{Abstract}

This paper critically reflects on the Scottish Adult Support and Protection study (the ASP study), a research project conducted at a time when "adult protection" was understood in Scottish policies to be the professional response to "abuse". During the course of analysing the ASP study data, it became apparent that practitioners themselves did not necessarily construct "abuse" and "adult protection" concerns as coterminous categories. Some examples are recounted to illustrate the potentially more partial, less linear relationship between these categories in practice than in policy constructions. The paper concludes with suggestions for further research into professionals' constructions of "adult protection" concerns. It explains why such research would have continuing, if not greater, relevance in the context of recent Scottish policy moves to re-conceptualise adult protection as a response not to "abuse" but to "harm".

Keywords: adult protection; adult safeguarding; adult abuse; harm; vulnerability

Subject categories: adult protection < social care services

Word count: 6998 excluding abstract. 


\section{Introduction}

The Scottish Adult Support and Protection (ASP) study collected information about multi-agency adult protection activity in Scotland prior to 2008. The research comprised 23 case studies where a single "adult at risk", together with the network of supports surrounding her or him, represented a single case. There was a particular focus in the study and its associated report on interagency collaboration in adult protection work, with important recommendations made for improvements in the context of Scottish policy and legislation which was changing at that time (Hogg et al., 2009a; 2009b; Mackay, 2008). This paper is connected to a further analysis of the ASP study dataset with a different approach and emphasis, however, and in this sense concerns a secondary or "data re-use" study (Moore, 2007). The further analysis began as an exploration of practice definitions of "abuse". However, it soon emerged that concerns described by professionals as alleged "abuse" and concerns which they judged to require an "adult protection" response did not always coincide. The focus of the analysis was changed to explore the types of concerns judged by professionals to require an "adult protection" response. The findings of this analysis will appear elsewhere. Meanwhile, this paper sets out the initial difficulty in more detail: namely, the inapplicability to the dataset of an analysis procedure based on the prescriptions of policy. This difficulty is important data in and of itself, demonstrating a more complex relationship between conceptualisations of "abuse" and conceptualisations of "adult protection" in practice than in policy. The paper follows an established qualitative tradition, then, of drawing new insights into research topics from 
reflexive consideration of the process of research (Mason, 2002; Stanley \& Wise, 1993; Valentine, 2007), including how researchers' investigations evolved as their first premises were challenged (Michael, 2004).

The abuse and protection of "vulnerable adults", or "adult support and protection" as it is now known in Scotland, has gathered pace as a UK policy concern over the previous two decades (Mackay, 2008; Penhale \& Parker, 2008). Research into the nature of the task and its associated challenges has gathered pace in tandem. For instance, studies have examined the successes and challenges of partnership working in adult protection in England and Wales (Manthorpe et al., 2010; McCreadie et al., 2008; Penhale et al., 2007); the effectiveness of English and Welsh regulatory frameworks in adult protection (Penhale et al., 2007); the relationship of abuse to service environments and cultures (Cambridge, 1999; White et al., 2003); and the experience and knowledge of front-line staff with respect to protection policies (McCreadie et al., 2008; Northway et al., 2007; Rees \& Manthorpe, 2010). Indeed, a number of previous studies have shown that professionals struggle to define "abuse" in the context of adult protection, often offering definitions in the abstract which are inconsistent with each other and with policy definitions. This tends to raise concerns that adult protection policies are being implemented incompletely and in inconsistent ways (McCreadie et al., 2008; Parley, 2010; Taylor \& Dodd, 2003). The suggestions of this paper have much in common with these findings, but also raise new questions about their implications. Specifically, this paper raises questions about the simplicity and linearity of the relationship between the identification of a phenomenon labelled as "abuse" and the instigation of "adult protection" interventions in 
practice, in contradiction to policies in place at the time and at the research sites of the ASP study. This has important implications for the relationship between policy stipulations and practice interpretations, which transcend the specific policy context of the ASP study.

Following a preliminary note on the practical significance of research into the use of terms and concepts, this paper opens by reviewing some debates around the nature of "abuse". The ASP study is then briefly outlined, followed by the analysis which prompted these critical reflections. Problems with the term and concept of "abuse" are then discussed in depth, with reference to anonymised examples from the ASP study dataset. This section of the paper should not be seen as a report of research findings so much as a reflexive commentary on observations and new questions which arose during the process of analysis. The dataset does not provide a comprehensive overview of the relationship between practice constructions of "abuse" and practice constructions of "adult protection" concerns, because this specific interest developed subsequent to the generation of the data. On the contrary, this section opens by noting how rarely the dataset indicates whether professionals had classified concerns as "abuse" or not, whether or not they had classified them as "adult protection" concerns. Drawing on selected examples the section then recounts some further ways in which the policy stipulation that "abuse" would first be identified, and "adult protection" would then follow, did not consistently match the evidence of the dataset. The concluding section makes the case for more focused research into the meaning of these indications. This section also outlines shifts in Scottish law and policy from the terminology of "abuse" to the terminology of "harm" since 
the ASP study was undertaken, and explains why these shifts have not lessened the relevance of the themes raised here.

\section{A note on the significance of terms and concepts}

The analysis on which this paper reflects took a broadly constructionist approach. That is, it took the view that all attempts to describe, understand and act on the social world incorporate interpretations of that world, and that these interpretations draw on frameworks of reference, or discourses, which are historically and culturally contingent (Foucault, 1972; Holstein \& Miller, 2003; Parker, 1998; Parton \& O'Byrne, 2000). For instance, discussions and actions within the framework of "adult protection" will involve particular ways of interpreting what "vulnerability" means, who might experience it and why; and particular ways of interpreting the role of the state in relation to individuals and social groups like families. Correspondence with "reality" is not a straightforward, nor a sufficient criterion for the evaluation of interpretations and frameworks of interpretation from a constructionist perspective. However, interpretations and frameworks can be evaluated against their effects, given that they lead to particular individual and collective actions, and hence impact on people's lives (Bacchi, 1999). It is these impacts which are worth critiquing, and not terms or concepts per se.

Nevertheless, if "adult protection" is not assumed to be a direct and benign response to the nature of problems in the "real" world, but instead a constructed discourse whose tenets ought to bear examination, it matters 
which concerns come within its remit and how they are understood. It matters whether the concepts used to shape and justify the discourse at policy level bear any resemblance to the concepts used when applying the discourse in practice. It matters because a shared language is required to evaluate contemporary adult protection/safeguarding discourse as it manifests itself in impacts on certain adults' lives. It is in this sense that interpretations of the centrality of "abuse" to "adult protection" which are significantly different between policy and practice have practical significance. It is to debates about "abuse" that this paper now turns.

\section{The nature of "abuse"}

"Abuse" has been constructed differently at different times and in reference to different groups of individuals (Johnson et al., 2010). It is a relative concept, defined in counterpoint to prevailing norms of acceptable experience. For instance, placement of a parent with dementia in a nursing home might be defined as "abuse" or as normal and necessary in different cultural and historical contexts (Kosberg et al., 2003). Definitions of "abuse" also shift with a society's capacity to effect changes in assumedly harmful conditions (Lockyer, 2010). Where requiring children to work is an economic necessity, for instance, this may be less likely to be approached as "abuse". Bound up with the concept of "abuse" are ideas about "vulnerability" and/or of a power imbalance between the victim and the perpetrator. This means that many definitions of "abuse" refer not only to types of action but to types of 
relationship: for instance, certain actions by a man towards his female partner (Scottish Executive, 2003), or by a therapist towards a patient (Brown \& Keating, 1998).

Those with a stake in the discourse have debated definitions of "abuse" in particular respect of "adults at risk" for some considerable time. Many such debates have been specific to particular groupings of adults, for instance learning disabled adults (Brown \& Turk, 1992) or older adults (Brammer \& Biggs, 1998). Some have debated definitions for research purposes specifically (Dixon et al., 2010), or for policy purposes specifically (Better Government for Older People/Action on Elder Abuse, 2004). The relevance to definitions of the following factors has been repeatedly discussed:

- The nature of the adult's "vulnerability", including her/his membership of assumedly "vulnerable" groups (e.g. those with impairments; those without mental capacity; those over a specified age) (Dunn et al., 2008; Slater, 2005);

- The perpetrator's relationship to the victim, in particular any imbalance of power and any relationship implying trust (Dixon et al., 2010; Hugman, 1995);

- The perpetrator's intent (Brammer \& Biggs, 1998; Brown \& Turk, 1992);

- The origin of the concern in acts of commission or omission (Brammer \& Biggs, 1998);

- The impact on the victim (Brammer \& Biggs, 1998; Brown \& Turk, 1992); 
- Whether the action/situation is repeated over time (Selwood et al., 2007).

In recent years UK adult protection policy definitions of "abuse" have grown increasingly inclusive (Brammer \& Biggs, 1998), for example resisting any exclusion criteria in respect of setting, identity or intent of person(s) perpetrating harm (Department of Health, 2000). Indeed, some campaigning groups have characterised the discourse as over-inclusive, patronising and discriminatory, demanding that it be curtailed (Disability Agenda Scotland, 2006; Inclusion Scotland, 2006). Meanwhile, interviews and focus groups with professionals charged with implementation reveal working definitions of "abuse" which are inconsistent and often narrower than policy definitions, for instance which exclude acts of omission, or unintentional harm, or particular types of perpetrator (McCreadie et al., 2008; Parley, 2010; Taylor \& Dodd, 2003). This paper builds on these studies, as noted, by problematising the links which could be assumed between professional comfort or discomfort with the term and concept of "abuse", and the actual implications of this for an "adult protection" response.

\section{The ASP study}

The ASP study investigated adult protection work in Scotland prior to the implementation of the Adult Support and Protection (Scotland) Act 2007. The aim of the study was to provide baseline data about agency and interagency protective practice to inform training and guidance, and to provide 
groundwork in methodological terms for the development of audit tools and potentially for post-Act comparative research (Hogg et al., 2009a). The project centred on in-depth case studies of practice with 23 "adults at risk" across four council areas in Scotland. This was a convenience sample in the sense that cases were identified by social work managers and staff where they knew of them and were prepared to approach the adult and/or their representative for consent. However there were elements of stratification to ensure that family, community and managed settings were included in the sample and that older age $(n=9)$, learning disability $(n=12)$, physical disability $(n=1)$ and mental health problems $(n=11)$ were all represented, sometimes in combination. Given variations in the terminology in use at the time and the exploratory nature of the ASP study, the criteria for inclusion were otherwise relatively non-specific. In particular, cases were not required to have followed particular formal procedures, but only to be considered to have involved some form of "adult abuse" or "adult protection" or "vulnerable adult" concern. In sum, the sample was wide-ranging to the extent that conceptualisations of these discourses themselves were wide-ranging: an important context for what follows.

Each case study involved documentary analysis, primarily of social work files, followed by semi-structured interviews with all involved professionals as far as this was possible. Detailed chronologies were then compiled of events and interactions over the course of each case, supplemented by professionals' explanations and reflections on the process of response. Primary analysis of the chronologies lead to a number of recommendations for improvements within and across the various agencies 
and committees engaged in implementing adult support and protection policy. For instance, we recommended a review of training at Scottish Government level, further development of independent advocacy services at local authority level and more structured strategies for communication at the level of the individual case (Hogg et al., 2009b). However, the further analysis to which this paper now turns represents a step back, if temporarily, from these types of applications to examine what professionals engaged with policy implementation actually considered themselves to be doing, and why. A brief outline of local policy stipulations at the time of the study is required to contextualise these questions. This outline is provided next.

\section{The further analysis in context}

At the time of the ASP study, Scottish "adult protection" policies had been developing at local authority level, often drawing on guidance to English local authorities (Department of Health, 2000), but less standardised in content and terminology than they are today. Nonetheless, all policies across the research sites conceptualised "adult protection" or "protection of vulnerable adults" as a response to alleged or actual "abuse". No policy required harmful actions or circumstances to have been intended, repeated or to have exceeded a specified "severity" in order to constitute "abuse". All recognised the potential for "abuse" in settings and relationships providing support and/or care, and also elsewhere particularly where there was an imbalance of power. Indeed, whilst there were some variations in inclusion and exclusion criteria with 
respect to perpetrator and setting (for instance some policies, but not others, stated that random attacks by strangers would usually not be defined as "abuse"), these criteria were generally flexible with scope for professional discretion in individual instances.

Given the sampling procedure described above, all 23 cases included in the further analysis can be understood, at the least, to have been judged to involve an adult "abuse/protection" issue by the professional who passed the case to us. However, two realisations raised the possibility of the further analysis, as originally conceived, on which this paper reflects. Firstly, different professionals working on each case did not necessarily view the suspicions or allegations and the appropriate response in the same way as each other and/or in the same way as the person who passed the case to us. Secondly, cases often involved multiple concerns and adverse circumstances, some of which were separated out and constructed by professionals as alleged "abuse" and some of which were not. For instance, a learning disabled man might have been subjected to alleged poor care/support, financial exploitation and violence at the hands of his family, and this might have been constructed as alleged "abuse". However, a further incident in which he reported being hit by a fellow user of his day centre might not have been constructed as alleged "abuse"; nor might the alleged failure of the centre to meet his personal care needs.

$<$ Table 1 about here> 
The analysis therefore began by reconstructing each "case" into a (usually) larger number of "concerns", as demonstrated by the first two columns of Table 1. Further columns were added to describe certain features of each concern, and hence to explore the relationship of these features to definitions of "abuse" in practice (Miles \& Huberman, 1994). The column headings were drawn from a review of the literature as outlined in the bullet-pointed list above. The column entries aimed to report participants' own understandings of each concern, in line with the research focus on construction at the practice level (Holstein \& Miller, 2003). These understandings were drawn or inferred from detailed notes from case files and interviews, including numerous and extensive verbatim quotations. Where data were missing or ambiguous, however, this was duly noted.

The analysis, to reiterate, changed course at this time. This was because it became apparent that, whilst practice definitions of alleged "abuse" and practice definitions of situations requiring an "adult protection" response often overlapped, they could not be assumed to fully coincide. A further column was added to the matrix as shown in Table 2. Its contents and their relationship to the features of each concern will be explored elsewhere. The next section explains the reasons for requiring the addition. The section draws on examples from the dataset, with identifying details removed or changed.

$<$ Table 2 about here>

\section{Problems with the term and concept of "abuse"}


One initial, striking feature of the completed matrix was the frequent absence of information about whether or not professionals considered a concern to constitute "abuse". This occurred where we had no recorded instance of professional(s) using this term and concept in their documentation or their interviews with us, and was sometimes true even where there had been an "adult protection" response. For instance, one woman with mild learning difficulties and fluctuating mental health problems alleged that she had been raped by a stranger in a park. An "adult support and protection" response was mounted according to the social work file, alongside a police inquiry. However it was not actually clear whether the alleged rape was conceptualised as alleged "abuse", as defined in the local "vulnerable adult support and protection" policy, because use of the terminology of "abuse" by professionals was not evidenced in our dataset. If the rape was thought of as "abuse", it was not clear whether all crimes against a service user would have been conceptualised as "abuse" by these professionals in this geographical area, or if something specific was considered to render this woman in these circumstances a "vulnerable adult", in addition to being the victim of a crime. Conversely, it was not clear whether several other crimes against service users included in the ASP study, in this local authority and others, triggered criminal action but no social work or multi-agency "adult protection" response because they were not viewed as "abuse", or if this disparity was best accounted for in some other way.

We had aimed to record all factors mentioned in documentation and research interviews which influenced intervention decisions, particularly the 
structure and contents of all social work "adult protection" recording forms. Therefore these frequent gaps in the dataset suggest that whether a concern was formally labelled as "abuse" or not was not a key factor in intervention decisions. Indeed, it was not clear whether professionals had explicitly discussed definitions of "abuse" at all in relation to almost all concerns; if these discussions took place they were not recorded and were not usually discussed with us.

Furthermore, in the minority of instances where definition of a concern as "abuse" had been explicitly debated and discussed, the conclusions reached did not necessarily underpin decisions about "adult protection" intervention. For instance, in one case professionals felt a mother was extremely, detrimentally over-protective of her disabled daughter, and they wished to intervene. The social worker quoted from the local policy definition of "emotional abuse" to convince a meeting that "adult protection" intervention might be warranted here. There were some differences of opinion about this definition. However, the majority of professionals involved appeared to concur, and "adult protection" processes proceeded. Construction of the circumstances as "abuse" did not precede perception of the need for "adult protection" action in this instance, then, but apparently came later to justify such action.

In some instances, the need for "adult protection" seemed to have been accepted uncontroversially by professionals, whilst a label for the concern of alleged "abuse" was accepted more reluctantly, resisted or rejected. For instance, one professional involved in the case of the disabled woman and her "over-protective" mother did not question the value of "adult protection" 
investigations and meetings but described the concerns as relating to "quality of life" and "denial of rights" in his research interview with us, rather than ever employing the term or concept of "abuse" as far as our dataset shows. Where concerns related to families perceived to be struggling to care for an older, ill and/or disabled relative, the terminology of "abuse" could be similarly scrupulously avoided in documentation and/or in research interviews, implying professional discomfort with policies' treatment of "neglect" as a subset of "abuse" in this type of circumstance. However, such concerns still sometimes triggered "adult protection" procedures. In one further case a woman with limited capacity to consent to sex had a range of sexual contacts with men both with and without learning difficulties themselves. One professional working with this woman accepted the need for "adult protection" action in relation to all of her sexual contacts, but characterised some as "more clearly abusive" than others, on the basis of the woman's stated wishes and the abilities and intent of each perpetrator.

The above examples support previous findings that some factors not prescribed by policies, particularly the perpetrator's intentions, can influence professionals' identification of "abuse" (e.g. Parley, 2010). However the examples further demonstrate that non-identification of "abuse", in apparent contradiction of relevant local policies, did not necessarily equate to absence of "adult protection" response. Nonetheless, the two absences did sometimes co-occur. In particular, we saw several examples of assaults and taunts by fellow users of care/support facilities, which were apparently neither conceptualised as "abuse" nor judged to require an "adult protection" 
response according to social work documentation. This was sometimes contrary to local policies operational at these times and places.

On the other hand, a label of "abuse" could sometimes be employed without "adult protection" processes being conceptualised as the best means of response. One case of a man with dementia living at home with his daughter was particularly interesting in this respect. Professionals reported that there were frequent verbal conflicts in this household and that since moving in with him, the daughter had curtailed her father's independence more than was necessary at this stage of his illness. The man also exhibited some behaviours which challenged his daughter, apparently setting the context for some harsh verbal recriminations and damaging attempts by the daughter at restraint. There were three brief entries into "adult protection" processes in the course of professional responses to these concerns, triggered by three occasions on which the man was noted to be bruised and/or on which he reported a "scuffle" with his daughter. These entries into formal processes were marked by completion of "adult protection" recording forms. Each such entry was reported to have been quickly concluded, with "no further action in relation to adult protection procedures" recommended following initial investigations of each incident. A senior social worker told us that the case was "adult protection apparently but in reality to do with family relationships". However, this interviewee used the description of "abuse" quite freely when discussing her concerns about the man's situation and his care/support. This interviewee's assessment of these concerns is interesting, in part, because it demonstrates a view of "adult protection" as a formal procedure clearly distinct from a "family support" approach. Other 
professionals, local authorities or agencies might not have seen the two as mutually exclusive, and so might not have conceptualised "adult protection" action as having been quickly concluded with this family. Nevertheless, the key point here is that this particular interviewee constructed "adult protection" and "abuse" in such a way, that she could describe the work with this father and daughter as involving interventions which were not "adult protection" interventions, to counter a situation comprising ongoing "abuse". Similarly, there were several cases in which managers of provider services referred to recorded instances of rough and/or incompetent manual handling as "physical abuse" and insults directed at service users as "verbal abuse" throughout their research interviews with us, but did not perceive a need for "adult protection" action at the time, as evidenced by their failures to refer to statutory agencies. Perhaps these participants had amended their terminology since their practice had been challenged by other agencies in the course of responding to these concerns, and/or in response to the known subject of our research. Conversely, perhaps this is a further demonstration of the term and concept of "abuse" having been applied in imprecise ways at the time of these incidents, with no clear relationship to any one means of professional response.

A further problem with the research expectation that identified "abuse" and/or "neglect" should equate to an "adult protection" response concerned the finer practice distinctions between singular incidents and cumulative situations. For instance in one case, neglect of an older woman's personal care was noted on recording forms as one aspect of "adult protection" concern when incidents of alleged violence triggered "adult protection" processes; however the longer-standing neglect had not triggered "adult protection" 
processes in and of itself. Moreover, in other cases, no single incident to which the individual had been subjected appeared to have been labelled as "abuse" or to have been recorded as an "adult protection" concern, in social work documentation at least. However, the case must have been judged to involve "adult protection" in some sense overall, not least because it was identified by social work for inclusion in our study. One such case involved a man with mental health problems who was repeatedly verbally taunted, assaulted and robbed by neighbours and their children, acquaintances and strangers. Work with this man focused on supporting him to make positive community connections and to be assertive and vigilant about his personal safety. "Adult protection" in this case, then, was about responding to a perceived, generic level of "vulnerability" rather than to particular incident(s) of "abuse".

\section{Discussion}

From the above observations, four broad conclusions might be proposed. Firstly, deliberations on the definition of a circumstance as "abuse" or not were not central enough to practice to be documented and might not consistently have been discussed at all in the ASP study cases. Secondly, "abuse" and "adult protection" issues were not necessarily perceived to be the same in practice. On the contrary, identification of the latter seemed of more immediate import and seemed sometimes to precede or even replace identification of the former. Furthermore, and thirdly, "adult protection" issues 
could be perceived in practice where a label of "abuse" was explicitly rejected, and "adult protection" processes could be deemed irrelevant where a label of "abuse" was applied. Consequently, and fourthly, "abuse" might be proposed to be an unhelpfully imprecise and emotive term and concept to professionals, either for guiding or describing practice judgements about the need for an "adult protection" response.

From these tentative conclusions it can be inferred that, though professionals' answers have been inconsistent with each other's and with policies when asked for abstract definitions of "abuse" in research interviews (Parley, 2010; Taylor \& Dodd, 2003), this is not a straightforward indicator that "adult protection" policies have been inconsistently applied. Rather, "abuse" and "adult protection" issues appear distinct in practice, with the latter category considerably broader than the former in its scope. Nonetheless, ASP study professionals did not mount "adult protection" responses to every type of concern labelled as "abuse" in policies, therefore differing from policies only in their use of terminology. On the contrary, the scope of "adult protection" was also narrowed to some degree by allowances made for some "perpetrators" in some circumstances: especially service user "perpetrators" as well as some concerns in families. In particular respect of the latter, however, it is important to note that "adult protection" intervention was itself a concept which meant different, broader or narrower things to different professionals.

These critical reflections highlight the need for more research which, through examination and discussion of their practice, explores professionals' perspectives on what "adult protection" or "adult support and protection" or 
"adult safeguarding" fundamentally is, and what it is fundamentally for. The fit between practice and policy might then be more fully examined, on the understanding that both practice and/or policy might require adjustment if mismatches run deep. Such research will take place in a policy context different from that of the ASP study, however, as explained below.

Scottish policy shift from "abuse" to "harm"

Scottish policy shifted in a number of ways with the implementation of the Adult Support and Protection (Scotland) Act 2007 (the ASPA) in late 2008. In particular, "adult support and protection" was re-conceptualised by the Scottish Government as a response to "harm" rather than "abuse". "Harm" is defined to include "all harmful conduct", with no exclusion criteria in terms of the perpetrator(s)' identity or intent, and with the explicit inclusion of "selfharm" (ASPA s.3(2); s.53(1)). The de-stigmatisation of family carers whose relative requires protective intervention was an explicit intention of this change (Scottish Parliament Information Centre, 2007).

The following discussion proposes why the issues raised above are still of relevance in this transformed context. Key to this argument is the distinction between a term and a concept. Put differently, it is the distinction between "abuse"/"harm" functioning as a descriptor or as a determinant of the types of concern which might receive an "adult protection" response. "Abuse" would be functioning as a descriptor if a concern was first singled out as requiring an "adult protection" response, and was then referred to as "abuse" because this 
is the accepted label for issues requiring this type of response. Conversely, "abuse" would be functioning as a determinant if a concern was first identified to constitute a distinct phenomenon known as "abuse", and then received an "adult protection" response as a consequence of this. The policies in place at the time of the ASP study seemed to imply the latter sequence. However the indicators outlined here suggest that "abuse" was not, or was not consistently, functioning as a determinant. The identification of "adult protection" concerns seemed independent of and/or prioritised over the identification of "abuse" in some of the above examples. Nor was "abuse" a particularly effective descriptor, because some professionals were reluctant to describe some concerns which they had identified as "adult protection" concerns to constitute "abuse".

From a professional perspective, then, "harm" might indeed be a more effective descriptor of those concerns which receive an "adult [support and] protection" response. It is a term which can be more broadly applied because it avoids the moralising, stigmatising overtones of "abuse". The question remains, however, as to whether the concept of "harm" can function as a determinant of "adult protection" concerns, and if not, what does determine which concerns professionals construct in this way? Two points are pertinent to the first part of this question. Firstly, policy constructions of "adult protection" concerns prior to the ASPA (i.e. "abuse" as defined in local authority level policies) bore limited relationship to practitioner constructions of "adult protection" concerns. This confers doubt on any assumed equivalence between policy constructions of "adult protection" concerns following the ASPA (i.e. "harm" as defined by this legislation) and current practitioner 
constructions of "adult protection" concerns. Secondly, like "abuse" before it, "harm" in "adult support and protection" policy has a different meaning from the same term as employed in everyday speech. For example, "harm" in "adult support and protection" terms excludes potential harms which fall outside the remits of "adult support and protection" professionals, such as those harms potentially inflicted by social policies themselves (Biggs, 1996). Conversely, only some of the harms these professionals can work to avoid are included, unless all community care services are to be re-conceptualised as "adult support and protection" services, because they also increasingly seek to manage risk (Kemshall, 2010; Stalker, 2003; Webb, 2006). The point here is that "harm" for "adult support and protection" purposes does not have a selfevident meaning, but is understood in the context of its history: that is, in the context of the increasingly broadening conceptions of "abuse" which were its forerunners. And this raises the likelihood that current practitioner interpretations of "harm" continue to be influenced by pre-existing understandings of what constitutes an "adult protection" concern and, indeed, what types of processes might ensue (more or less flexible processes for instance; or more or less punitive) when this label is applied (c.f. Brown \& Stein, 1998). All of which considerations lead back to the need for more research to explore practitioners' perspectives on what "adult support and protection" fundamentally means in Scotland and elsewhere today, and what issues it is fundamentally intended to address.

\section{Conclusion}


"Adult protection" is a constructed discourse, whose interpretation of such issues as "vulnerability" and the role of the state in relation to the individual and family ought to be open to evaluation. The original spur to the development of the discourse was the recognition of a phenomenon labelled as "abuse". Indeed, the power relations understood to be inherent in "abuse" served to justify the power relations inherent in "adult protection" services themselves: that is, the justification of state intervention into the lives of certain "vulnerable" adults in certain situations.

This paper has shown that practitioners represented in the ASP study found neither the term nor the concept of "abuse" consistently helpful, either in identifying or in describing "adult protection" concerns. This raises questions about the relationship of practice interpretations to policy stipulations, and about the criteria under which concerns do become classified in practice as "adult protection" concerns. This paper has further argued that, whilst "harm" in recent Scottish law and policy may prove a more acceptable descriptor of those concerns which are classified by professionals as "adult support and protection" concerns, it does little to clarify what determines whether concerns are constructed in this way. This is an important question to have answered, however, if the discourse of "adult protection" is to be debated and evaluated in a way which bears meaningful relation to its effects on people's lives. Part of what is needed to progress forwards from this juncture is a fuller understanding of practitioners' interpretations of the discourse through their practice. More practice-based research will help to make this clear. 
Acknowledgements: The Scottish Adult Support and Protection study was funded by the Scottish Government and Capability Scotland, and was undertaken by the White Top Research Unit, University of Dundee in collaboration with Age Concern Scotland. The PhD of which this publication forms a part is funded by the Economic and Social Research Council. However the views expressed in this paper are the author's own. 


\section{References}

Bacchi, C. L. (1999) Women, Policy and Politics: The Construction of Policy Problems, London, Sage.

Better Government for Older People/Action on Elder Abuse. (2004) Placing Elder Abuse within the Context of Citizenship: A Policy Discussion Paper, London, BGOP/AEA.

Biggs, S. (1996) 'A family concern: elder abuse in British social policy', Critical Social Policy, 16, pp. 63-88.

Brammer, A., \& Biggs, S. (1998) 'Defining elder abuse', Journal of Social Welfare and Family Law, 20(3), pp. 285-304.

Brown, H., \& Keating, F. (1998) "We're doing it already...': adult protection in mental health services', Journal of Psychiatric and Mental Health Nursing, 5, pp. 273-280.

Brown, H., \& Stein, J. (1998) 'Implementing adult protection policies in Kent and East Sussex', Journal of Social Policy, 27(3), pp. 371-396.

Brown, H., \& Turk, V. (1992) 'Defining sexual abuse as it affects adults with learning disabilities', Mental Handicap, 20, pp. 44-55.

Cambridge, P. (1999) 'The first hit: a case study of the physical abuse of people with learning disabilities and challenging behaviours in a residential service', Disability and Society, 14(3), pp. 285-308.

Department of Health. (2000) No Secrets: guidance on developing and implementing multi-agency policies and procedures to protect vulnerable adults from abuse, London, HMSO.

Disability Agenda Scotland (2006) Evidence to the Health Committee on the Adult Support and Protection (Scotland) Bill, from http://www.scottish.parliament.uk/business/committees/health/reports06/her06-16-05.htm\#WrittenEvidence4

Dixon, J., Manthorpe, J., Biggs, S., Mowlam, A., Tennant, R., Tinker, A., \& McCreadie, C. (2010) 'Defining elder mistreatment: reflections on the United Kingdom Study of Abuse and Neglect of Older People', Ageing and Society, 30(3), pp. 403-420.

Dunn, M. C., Clare, I. C. H., \& Holland, A. J. (2008) 'To empower or to protect? Constructing the 'vulnerable adult' in English law and public policy', Legal Studies, 28(2), pp. 234-253.

Foucault, M. (1972) The Archaeology of Knowledge, London, Tavistock.

Hogg, J., Johnson, F., Daniel, B., \& Ferguson, A. (2009a) Interagency Collaboration in Adult Support and Protection in Scotland: Processes and Barriers. Volume 1: Main Report, Dundee, White Top Research Unit: University of Dundee.

Hogg, J., Johnson, F., Daniel, B., \& Ferguson, A. (2009b) Interagency Collaboration in Adult Support and Protection in Scotland: Processes and Barriers: Volume 2: Recommendations, Dundee, White Top Research Unit, University of Dundee.

Holstein, J. A., \& Miller, G. (2003). Social constructionism and social problems work. In J. A. Holstein \& G. Miller (Eds.), Challenges and Choices: Constructionist Perspectives on Social Problems. New York: Aldine de Gruyter. 
Hugman, R. (1995) 'The implications of the term 'elder abuse' for problem definition and response in health and social welfare', Journal of Social Policy, 24(4), pp. 493-507.

Inclusion Scotland (2006) Evidence to the Health Committee on the Adult Support and Protection (Scotland) Bill, from http://www.scottish.parliament.uk/business/committees/health/reports06/her06-16-05.htm\#WrittenEvidence5

Johnson, F., Hogg, J., \& Daniel, B. (2010) 'Abuse and protection issues across the lifespan: reviewing the literature', Social Policy and Society, 9(2), pp. 291304.

Kemshall, H. (2010) 'Risk rationalities in contemporary social work policy and practice', British Journal of Social Work, 40(4), pp. 1247-1262.

Kosberg, J. I., Lowenstein, A., Garcia, J. L., \& Biggs, S. (2003) 'Study of elder abuse within diverse cultures', Journal of Elder Abuse and Neglect, 15(3-4), pp. 7189.

Lockyer, A. (2010). Children's citizenship revisited, Paper presented at the Interrogating 'Harm' and 'Abuse' symposium. Stirling University, 31st March 2010.

Mackay, K. (2008) 'The Scottish adult support and protection legal framework', Journal of Adult Protection, 10(4), pp. 25-36.

Manthorpe, J., Hussein, S., Penhale, B., Perkins, N., Pinkney, L., \& Reid, D. (2010) 'Managing relations in adult protection: a qualitative study of the views of social services managers in England and Wales', Journal of Social Work Practice, 24(4), pp. 363-376.

Mason, J. (2002) Qualitative Researching (2nd ed.), London, Sage.

McCreadie, C., Mathew, D., Filinson, R., \& Askham, J. (2008) 'Ambiguity and cooperation in the implementation of adult protection policy', Social Policy and Administration, 42(3), pp. 248-266.

Michael, M. (2004). When things go wrong. In C. Seale (Ed.), Researching Society and Culture (2nd ed.). London: Sage.

Miles, M. B., \& Huberman, A. M. (1994) Qualitative Data Analysis: An Expanded Sourcebook (Second ed.), London, Sage.

Moore, N. (2007) '(Re)using qualitative data?' Sociological Research Online, 12(3), pp. http://www.socresonline.org.uk/12/13/11.html.

Northway, R., Davies, R., Mansell, I., \& Jenkins, R. (2007) "Policies don't protect people, it's how they are implemented': policy and practice in protecting people with learning disabilities from abuse', Social Policy and Administration, 41(1), pp. 86-104.

Parker, I. (Ed.). (1998). Social Constructionism, Discourse and Realism. London: Sage.

Parley, F. (2010) 'The understanding that care staff bring to abuse', Journal of Adult Protection, 12(1), pp. 13-26.

Parton, N., \& O'Byrne, P. (2000) Constructive Social Work: Towards a New Practice, Basingstoke, Palgrave.

Penhale, B., \& Parker, J. (2008) Working with Vulnerable Adults, Abingdon, Routledge.

Penhale, B., Perkins, N., Pinkney, L., Reid, D., Hussein, S., \& Manthorpe, J. (2007) Partnership and Regulation in Adult Protection: The Effectiveness of MultiAgency Working and the Regulatory Framework in Adult Protection, University of Sheffield/ KCL. 
Rees, P., \& Manthorpe, J. (2010) 'Managers' and staff experiences of adult protection allegations in mental health and learning disability residential services: a qualitative study', British Journal of Social Work, 40, pp. 513-529.

Scottish Executive. (2003) Preventing Domestic Abuse: A National Strategy, Edinburgh, Scottish Executive.

Scottish Parliament Information Centre (2007) Passage of the Adult Support and Protection (Scotland) Bill 2007: summary, from http://www.scottish.parliament.uk/business/bills/62adultSupport/documents/62-AdultSupportandProtectionBillsummary.pdf

Selwood, A., Cooper, C., \& Livingston, G. (2007) 'What is elder abuse - who decides?' International Journal of Geriatric Psychiatry, 22, pp. 1009-1012.

Slater, P. (2005) 'Elder abuse, adult protection and social care: developments in New Labour policy', Journal of Adult Protection, 7(3), pp. 33-37.

Stalker, K. (2003) 'Managing risk and uncertainty in social work: a literature review', Journal of Social Work, 3(2), pp. 211-233.

Stanley, L., \& Wise, S. (1993) Breaking Out Again: Feminist Ontology and Epistemology, London, Routledge.

Taylor, K., \& Dodd, K. (2003) 'Knowledge and attitudes of staff towards adult protection', Journal of Adult Protection, 5(4), pp. 26-32.

Valentine, C. (2007) 'Methodological reflections: attending and tending to the role of the researcher in the construction of bereavement narratives ', Qualitative Social Work, 6(2), pp. 159-176.

Webb, S. A. (2006) Social Work in a Risk Society: Social and Political Perspectives, Basingstoke, Palgrave Macmillan.

White, C., Holland, E., Marsland, D., \& Oakes, P. (2003) 'The identification of environments and cultures that promote the abuse of people with intellectual disabilities: a review of the literature ', Journal of Applied Research in Intellectual Disabilities, 16, pp. 1-9. 
Table 1: First version of matrix, partially completed to show the distinction between a "case" and its constituent "concerns"

\begin{tabular}{|c|c|c|c|c|c|c|c|c|c|}
\hline Case & Concern & $\begin{array}{l}\text { Was the } \\
\text { concern } \\
\text { constructed } \\
\text { as "abuse"? } \\
\text { (Expand on } \\
\text { any explicit } \\
\text { reasons } \\
\text { given by } \\
\text { workers/ } \\
\text { any } \\
\text { differences } \\
\text { of view) }\end{array}$ & $\begin{array}{l}\text { (How) was } \\
\text { the victim } \\
\text { considered } \\
\text { to be } \\
\text { vulnerable } \\
\text { (in general } \\
\text { and/or in } \\
\text { respect of } \\
\text { this } \\
\text { concern)? }\end{array}$ & $\begin{array}{l}\text { If there was } \\
\text { understood } \\
\text { to be a } \\
\text { perpetrator, } \\
\text { who was it } \\
\text { thought to } \\
\text { be? What } \\
\text { was } \\
\text { his/her/its } \\
\text { relationship } \\
\text { to the } \\
\text { victim? }\end{array}$ & $\begin{array}{l}\text { What was } \\
\text { known/ } \\
\text { understood } \\
\text { about the } \\
\text { perpetrator's } \\
\text { intent? }\end{array}$ & $\begin{array}{l}\text { Was the } \\
\text { concern } \\
\text { understood } \\
\text { to involve } \\
\text { acts of } \\
\text { commission } \\
\text { or acts of } \\
\text { omission? }\end{array}$ & $\begin{array}{l}\text { What was } \\
\text { understood } \\
\text { to be the } \\
\text { impact on } \\
\text { the victim? } \\
\text { How did } \\
\text { (s)he } \\
\text { experience } \\
\text { the } \\
\text { situation? }\end{array}$ & $\begin{array}{l}\text { Was the } \\
\text { action/ } \\
\text { situation } \\
\text { (thought } \\
\text { to be) } \\
\text { singular } \\
\text { or } \\
\text { repeated } \\
\text { over } \\
\text { time? }\end{array}$ & Notes \\
\hline \multirow[t]{7}{*}{$\begin{array}{l}\text { 1. Joe } \\
\text { Parker }\end{array}$} & $\begin{array}{l}\text { a) Family alleged to } \\
\text { provide insufficient } \\
\text { personal care }\end{array}$ & & & & & & & & \\
\hline & $\begin{array}{l}\text { b) Family suspected to } \\
\text { misuse JP's benefits }\end{array}$ & & & & & & & & \\
\hline & $\begin{array}{l}\text { c) JP hit by mum "in heat } \\
\text { of the moment" during } \\
\text { incident of JP's } \\
\text { challenging behaviour }\end{array}$ & & & & & & & & \\
\hline & $\begin{array}{l}\text { d) JP alleges he was hit } \\
\text { by fellow service user }\end{array}$ & & & & & & & & \\
\hline & $\begin{array}{l}\text { e) JP further bruised } \\
\text { following alleged restraint } \\
\text { by brother }\end{array}$ & & & & & & & & \\
\hline & $\begin{array}{l}\text { f) Family complain pad } \\
\text { regularly not changed at } \\
\text { day centre }\end{array}$ & & & & & & & & \\
\hline & & & & & & & & & \\
\hline
\end{tabular}

N.B. Fictional case constructed to illustrate use of analysis tool. 
Table 2: Second version of matrix, showing the addition of a new column

\begin{tabular}{|c|c|c|c|c|c|c|c|c|c|c|}
\hline Case & Concern & $\begin{array}{l}\text { Was the } \\
\text { concern } \\
\text { constructed } \\
\text { as “abuse"? } \\
\text { (Expand on } \\
\text { any explicit } \\
\text { reasons } \\
\text { given by } \\
\text { workers/ } \\
\text { any } \\
\text { differences } \\
\text { of view) }\end{array}$ & $\begin{array}{l}\text { Was the } \\
\text { concern } \\
\text { constructed } \\
\text { as an "adult } \\
\text { protection" } \\
\text { issue? } \\
\text { (Expand on } \\
\text { any explicit } \\
\text { reasons } \\
\text { given by } \\
\text { workers/ } \\
\text { any } \\
\text { differences } \\
\text { of view) }\end{array}$ & $\begin{array}{l}\text { (How) was } \\
\text { the victim } \\
\text { considered } \\
\text { to be } \\
\text { vulnerable } \\
\text { (in general } \\
\text { and/or in } \\
\text { respect of } \\
\text { this } \\
\text { concern)? }\end{array}$ & $\begin{array}{l}\text { If there was } \\
\text { understood } \\
\text { to be a } \\
\text { perpetrator, } \\
\text { who was it } \\
\text { thought to } \\
\text { be? What } \\
\text { was } \\
\text { his/her/its } \\
\text { relationship } \\
\text { to the } \\
\text { victim? }\end{array}$ & $\begin{array}{l}\text { What was } \\
\text { known/ } \\
\text { understood } \\
\text { about the } \\
\text { perpetrator's } \\
\text { intent? }\end{array}$ & $\begin{array}{l}\text { Was the } \\
\text { concern } \\
\text { understood } \\
\text { to involve } \\
\text { acts of } \\
\text { commission } \\
\text { or acts of } \\
\text { omission? }\end{array}$ & $\begin{array}{l}\text { What was } \\
\text { understood } \\
\text { to be the } \\
\text { impact on } \\
\text { the victim? } \\
\text { How did } \\
\text { (s)he } \\
\text { experience } \\
\text { the } \\
\text { situation? }\end{array}$ & $\begin{array}{l}\text { Was the } \\
\text { action/ } \\
\text { situation } \\
\text { (thought to } \\
\text { be) } \\
\text { singular or } \\
\text { repeated } \\
\text { over time? }\end{array}$ & Notes \\
\hline
\end{tabular}

